\title{
Correction to: A Numerical Investigation of the Mean Free Path Distribution in the Knudsen Regime
}

\author{
Martijn G. Verbeek ${ }^{1}$
}

Published online: 14 May 2018

(c) Springer Science+Business Media B.V., part of Springer Nature 2018

\section{Correction to: Transp Porous Med https://doi.org/10.1007/s11242-018-1035-0}

In Eq. (11) there is a comma missing in the subscript: $t_{c j}$ should be replaced with $t_{c, j}$ and $t_{l c j}$ with $t_{l c, j}$. I apologize for the inconvenience.

The original article can be found online at https://doi.org/10.1007/s11242-018-1035-0.

$\bowtie \quad$ Martijn G. Verbeek gustafverbeek@gmail.com

1 Hoorn, The Netherlands 